\title{
The butler(s) DID it - dissociative identity disorder in cinema
}

Peter Byrne Kent Institute of Medical and Health Sciences, Canterbury, Kent

\begin{abstract}
Beginning with classic Hollywood melodramas of the 1940s, cinema has maintained a prolific output of films with their own take on mental illnesses-none more so than the rare syndrome of dissociative identity disorder (DID). DID films are a popular and enduring genre, whose influence can be seen throughout mainstream cinema. Exploration of DID in cinema is a useful exercise in that it touches on issues in film studies, psychiatry and the mythology around mental illness. Despite "detective story" narratives and conformity to the codes of the psychological thriller, DID representations correspond closely to contemporary thinking about its phenomenology and aetiology. That said, some films confuse DID with schizophrenia, and many reinforce two other misconceptions within film psychiatry: mental illness as violence and the belief that every mentally ill person harbours one "great dark secret". Those sceptical about DID have suggested that popular written accounts increase its profile: so too, powerful cinematic images may suggest the possibility of DID to susceptible people, including clinicians. Recent DID films reflect the real debate within psychiatry about the diagnostic validity and scientific basis of DID.

(F Med Ethics: Medical Humanities 2001;27:26-29)
\end{abstract}

\section{Introduction}

Me, Myself and Irene (2000) is the latest in a series of films depicting the psychiatric syndrome of Dissociative Identity Disorder (DID). Wrongly billed as a "schizophrenia comedy", it stars Jim Carrey as a state trooper "whose (two) split personalities fall for the same woman after he forgets to take his mood stabilisers". The film is not about schizophrenia, but it confuses this illness with DID. As such, it is best seen in the context of other DID films, comprising a distinct genre. The seminal DID film was The Three Faces of Eve (1957), overshadowing Lizzie, released the same year. Both were based on living persons. The Three Faces of Eve depicted a traumatic childhood incident leading to the development of three separate personalities, all of which are reconstituted during the emotional catharsis where Eve is confronted with these truths. The actual details of this true story have been told by the real Eve, Chris Costner Sizemore. After a long history of multiple childhood traumas, she presented with psychiatric symptoms, but initial cathartic treatment led to more personalities, a total of twenty-two. ${ }^{2}$ This presentation corresponds closely to the current conceptual framework of DID as a complex form of posttraumatic dissociative disorder, highly associated with a history of severe trauma, usually beginning at an early age. ${ }^{3}$

Art may be a harmless mirror to the world, but when film (art) imitates the condition of DID, interesting commonalities with the "reality" of the condition as well as fanciful departures from the real, throw light on this controversial syndrome.

Filmic representations of DID, formerly known as multiple personality disorder, adhere closely to the clinical syndrome, as described by Putnam ${ }^{3}$ and as defined in DSM-IV. ${ }^{4}$ Of the 22 DID films listed in table 1,12 are from the past decade, indicating the enduring popularity of the genre. Six (marked with asterisk) are "biopics", that is, they portray the "true story" of individuals with DID. In contrast to the cinematic representation of many psychiatric illnesses, to which users and professionals could object, these films in particular reflect current concepts, and could serve as teaching material for DID. ${ }^{4}$ In Madonna of the Seven Moons (1944), a woman dissociates and begins a new life as a gypsy following a sexual assault. Childhood trauma continues to have powerful aetiological status in more recent films: Prey of the Chameleon (1991), Raising Cain (1992), Color of Night (1994), Separate Lives (1994), Voices From Within (1994) and Never Talk To Strangers (1995). Most of the films in table 1 are detective stories in which the DID individual adds an extra layer of complexity to a "whodunnit" yarn, be it as thief (Maroc 7), detective (Night Visions), psychologist (Separate Lives) or victim (Color of Night). The majority of DID films are thrillers: Primal Fear (1996) comes with the distributors' plea not to reveal the surprise ending. ${ }^{5}$

\section{Table one: dissociative identity disorder} films

Broken Reality (1994)

Color of Night (1994)

Dressed To Kill (1980)

Fight Club (1999)

Five of $M e(1981)^{\star}$

Lizzie (1957)*

Madonna of the Seven Moons (1944)

Maroc 7 (1967)

Me, Myself, I (1992)

Mirage (1944)

Never Talk To Strangers (1995)

Night Visions (1990)

Positive ID (1987)^ 
Prey of the Chameleon (1991)

Primal Fear (1996)

Raising Cain (1992)

Separate Lives (1994)

Sybil $(1976)^{\star}$

The Love Butcher (1982)

The Three Faces of Eve (1957)*

Voices From Within (1994)

Voices Within: The Lives of Trudi Chase (1990)*

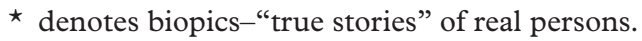

\section{Why DID?}

The question arises as to why cinema should turn so frequently to the unusual condition of DID for inspiration. The evolution of a character with DID provides the first clue: dramatic presentations with bizarre symptoms, which then give way to flashbacks and a variety of dissociative states. Cinema's seamless mastery of space and time, and its ability to represent different points of view, lends itself uniquely to these portrayals. Even more attractive to the potential producer is the dramatic moment of catharsis, where all is revealed (the "twist") and resolution occurs. For the melodrama (the "biopics" of table 1) this is cure, but in thrillers, the mystery is (re)solved. In addition to providing great scenes, DID films provide great roles. Actors must jump at the chance to evoke such drama, with the opportunity to immerse themselves in multiple method acting. Joanne Woodward and Ronald Coleman each won Oscars for The Three Faces of Eve and A Double Life (1947) respectively, while Sally Field was awarded an Emmy for the eponymous Sybil (1975). Trying to emulate Field, Shelley Long attempted to use a DID role to make the transition from comedy to drama, playing the lead in Voices Within: The Lives Of Trudi Chase.

Cinema's tendency to imitate itself is also relevant here. Many other films share the plot device where, owing to mental illness, one character assumes the role of another. These complement the DID genre: Cabinet of Dr Caligari (1919), Testament of Dr Mabuse (1933), Spellbound (1945), A Double Life, Psycho (1960), Magic (1978), Ninth Configuration (1979), The Shining (1980), The Long Kiss Goodnight (1996) and Shattered Images (1998). In all but Spellbound, murder is committed by the person who assumes the alternate identity. All are thrillers, and the suspense centres on that character being "out of control". These ten films are only a small sample of a longer list of similar films. Psycho, and its many imitators, form the psychokiller genre, which reinforces the public's perception of mental illness as violence. ${ }^{6}$ While these films probably owe some inspiration to Stevenson's Dr fekyll and $M r$ Hyde, they turn on hidden evil in a person tainted with mental illness. In these schemata, the unconscious is never a pleasant place, and the emerging dark personality has clear parallels with DID films. Both Raising Cain and Dressed To Kill demonise DID, with direct homage to Psycho. The transition from "regular guy" to mass murderer in Fight Club (1999) is also achieved through DID. Similar motifs were employed in The Talented Mr Ripley (1999), where the psychopathic Ripley assumes his victim's identity to evade detection and ease his guilt.

DID films are so established as a genre that they have been regularly parodied: Zelig (1983), The Man With Two Brains (1983), and Loose Cannons (1990). In Me, Myself, I (1992), Jo Beth Williams is listed in the credits as playing the roles of "Crazy" and "Sane" Diane. Trigger Happy (1997) begins with the release of "paranoid schizophrenic" gangster Vic from the "funny farm": the clinic decided it was too dangerous to let him out immediately, and so is staggering the process, releasing one personality at a time. Here, as in Me, Myself and Irene, mental illness is not feared, it is ridiculed. During a prolonged sequence in the film, Carrey physically fights himself for the dominant personality. At the height of Carrey's acting out, his companion reassures onlookers with the excuse that he is a "schizo".

If films are read as fantasy, additional analyses are possible. The fantasy is of an entirely different identity, a different life defined by different relationships. Fantasies are not always dark and murderous-as above-where violent impulses are projected onto an apparently "normal" individual. Recent films have explored the life choices women make, and presented alternative "what ifs" as fantasy-narratives: Peggy Sue Got Married (1986), Sliding Doors (1997) and Me, Myself and Irene (1999). The male equivalent gives nasty men a chance to change: Regarding Henry (1991), Mad About Harry (2000) and What Women Want (2000). In essence, these five films mirror Vertigo (1958), where James Stewart attempts to manufacture an entirely different fantasy-being from a real person. Though they are not DID films, they offer the spectator the fantasy of alternative identity within a cinema of limitless possibility.

\section{DID and schizophrenia}

One major consequence of DID films, and their spin-offs, has been the cinematic construction of schizophrenia as a "split personality" disorder. Although the films listed in table 1 conform closely to present day constructs of DID, many of them depart from this verisimilitude in equating the character's symptoms with schizophrenia. In reviews, the films listed in table 1 are often wrongly described as schizophrenia films: six are crossreferenced as schizophrenia in the Corel All-Movie Guide. ${ }^{7}$ Raising Cain was promoted with the following teaser: "When Jenny cheated on her husband, he didn't just leave, he split". Me, Myself and Irene plays DID for laughs, but within the film the Carrey character is diagnosed as having "advanced delusionary schizophrenia with involuntary narcissistic rage". The implication from the titles of each of Voices Within (1990) and Voices From Within (1994) is that the experience of hearing voices points to the rare diagnosis of DID, blurring the condition with schizophrenia. Further confusion arises with cinematic portrayals of psychopathic behaviour, espe- 
cially if the individual has contradictory motives, or leads a "double life": when Patricia Highsmith's novel The Talented Mr Ripley was reprinted, its dustcover carried a Sunday Times review of the work as "a haunting and harrowing study of a schizophrenic murderer". ${ }^{8}$

Confusing schizophrenia with DID is unfortunate, but the violence these films depict adds misunderstanding to misinformation. That misunderstanding equates "split personality" with "nice guy/murderer": the majority of the 52 films quoted in this article feature violence prominently. The perceived association between violence and schizophrenia has serious consequences, both for people with schizophrenia (and their families) and society in general. These misrepresentations of schizophrenia invoke the discourse: "schizophrenics" are either a violent threat or figures of fun. In addition to the distress such stereotypes cause, these misconceptions have a bearing on negative attitudes in the community to psychiatric patients living in their locality, with high levels of fear based on perceived threat. ${ }^{9}$

\section{The 'great dark secret' myth}

The Gabbards ${ }^{10}$ have written about The Three Faces of Eve as an example of "the cathartic cure". In both this film and the popular melodrama Ordinary People (1980), a forgotten childhood trauma is uncovered, and this derepression (sic) brings about recovery. The narrative structure of cinema readily embraces such concepts: the classic narrative provides a high degree of closure, such that every one of the questions raised in the course of the story is answered by the time the narrative is complete. Often, in order to provide this closure, a film will seek to imply a causal link between events. Within DID films (table 1), this is:

Childhood "trauma $\rightarrow$ repression $\rightarrow$ distress $\rightarrow$ diagnosis $\rightarrow$ derepression $\rightarrow$ cure".

Even the lightweight $M e$, Myself and Irene provides Carrey's repression of the hurt he felt when his wife left him as the sole explanation for his apparent illness. The DID protagonists of Sybil, Raising Cain, Color of Night, Separate Lives and Never Talk To Strangers have been traumatised so much, that their dissociation is represented as inevitable. Early in Sybil, her dissociative states are demonstrated, after which she explains to psychiatrist Dr Wilber (Joanne Woodward) that she once "woke up" two years later. Despite Sybil's presentation, with complex hallucinations and mood symptoms, Dr Wilber diagnoses DID to explain the patient's symptoms to her at the first visit, and effectively removes any other explanation of her difficulties: "If you are too scared to face something, then it just makes perfectly good sense to black out. Then you'll never have to know what you're scared of".

But cinema does not deserve all the blame for this psychiatric monomyth. In some of his early case histories, Freud claimed instant success, based on the cause and effect sequence described above. Of note, he advocated the following procedure:
"When I reached the same point with them [my patients] at which they maintained that they knew nothing more, I assured them that they did know it all the same and that they had only to say it; and I ventured to declare that the right memory would occur to them at the moment at which I laid my hand on their forehead. In that way I succeeded, without using hypnosis, in obtaining from the patients whatever was required for establishing the connection between the pathogenic scenes they had forgotten and the symptoms left over from those scenes". ${ }^{11}$

\section{The multiple personality disorder debate}

Multiple personality disorder has an entry in ICD 10, which begins: "this disorder is rare, and controversy exists about the extent to which it is iatrogenic, and culture-specific". ${ }^{12}$ Such scepticism has characterised the debate thus far on DID, with evidence of iatrogenesis, psychiatric comorbidity and epidemics reflecting interest in the disorder. ${ }^{13}$ There are marked differences in reported incidences of DID: Horen et $a l^{14}$ report DID in six per cent of psychiatric inpatients, but Rifkin et $a l,{ }^{15}$ using similar methods, found DID in only one per cent of their inpatients. $\mathrm{McHugh}^{16}$ investigated DID cases referred to Johns Hopkins' and concluded that all cases showed the "hand of the artisan" in presenting features and issues which arose during treatment. In this context the remarks quoted above of Freud and the fictional Dr Wilber are relevant: DID films tap directly into a rich vein of patients' preconceptions and therapists' zeal. Fahy ${ }^{13}$ proposes that the development and diagnosis of DID in themselves reflect contemporaneous literature. But DID films, and their imitators, have an even wider currency (through video and television) than written materials.

Color of Night (1994) was the last feature film which depicted a DID character entirely as victim. At the end of Never Talk To Strangers, Rebecca De Mornay, best known as the psychokiller from The Hand That Rocks The Cradle (1992), kills to prevent detection in full knowledge of her actions. In Fade (1995), the killer sarcastically tells psychologist and "dissociation expert" Linda Fiorentino that he must have killed her lover in a moment of "hysterical blindness". Primal Fear (and I will reveal the ending) concludes with murder suspect Edward Norton's triumphant admission he was faking DID all along. Primal Fear hits home hard in challenging both his motives and the validity of the syndrome. Art imitates Life, but Life can now fake the Art: DID may have had its day. Perhaps Hollywood has pushed out the boat too far-so far that its flimsy structure cannot withstand the rough seas. Some DID films have done much harm to people with schizophrenia, but faithful and "over the top" portrayals of DID may have done psychiatry a favour.

Peter Byrne, MA, MB, MRCPsych, is a Consultant Psychiatrist and Senior Lecturer in Psychiatry at the Kent Institute of Medical and Health Sciences, Canterbury, Kent. 


\section{References}

1 Patterson P. Megaphone: Carrey on .... The Guardian 1999 Apr 3: 21 .

Sizemore C. I'm Eve. Garden City, New York: Doubleday, 1977.

3 Putnam,FW. Resolved: multiple personality disorder is an individually and socially created artefact-negative. Fournal of th American Academy of Child and Adolescent Psychiatry 1995;34 960-2.

4 American Psychiatric Association. Diagnostic and statistical manual of mental disorders. Washington: American Psychiatric Association, 1994.

5 Matthews P. Primal Fear. Sight and Sound 1996;6:50-1.

6 Byrne P. The fall and rise of the movie psychokiller. Psychiatric Bulletin 1998;22:174-6. 7Corel all-movie guide. CD-rom version, (C) Corel, 1995.

8 Highsmith P. The talented Mr Ripley. London: Vintage, 1999.

9 Wolff G, Pathare S, Craig T, Leff, J. Community attitudes to mental illness. British fournal of Psychiatry 1996;168:183-90.
10 Gabbard K, Gabbard G. Psychiatry and the cinema [2nd ed]. Chicago: University of Chicago Press, 1999.

11 Freud S. Second lecture. In: Strachey J, ed. Five lectures on psychoanalysis (1909). London: Penguin Books, 1977.

12 World Health Organization. The ICD-10 classification of mental and behavioural disorders. Geneva: World Health Organization, 1992.

13 Fahy T. The diagnosis of multiple personality disorder: a critical review. British fournal of Psychiatry 1988;153:597-606.

14 Horen SA, Leichner PP, Lawson JS. Prevalence of dissociative symptoms and disorders in an adult psychiatric inpatient population in Canada. Canadian fournal of Psychiatry 1995;40: 185-91.

15 Rifkin A, Ghisalbert DO, Dimatou S, Charles J, Sethi M. Dissociative identity disorder in psychiatric inpatients. American Fournal of Psychiatry 1998;155:844-5.

$16 \mathrm{McHugh}$ PR. Witches, multiple personalities and other psychiatric artefacts. Nature Medicine 1995;1:110-14. 